\title{
Analysis on the Current Situation of Creating Low - carbon Cities - Taking Chengdu as an Example
}

\author{
Liang Chen ${ }^{1, a}$ Yong Zhong ${ }^{1, b}$ Rui Jiang ${ }^{1, c}$ \\ ${ }^{1}$ Jincheng College of Sichuan University, Sichuan, Chengdu, China, 611731

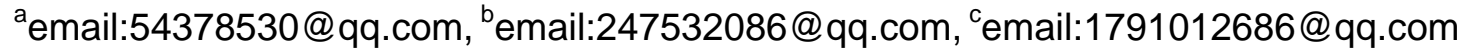

Keywords: Current Situation, Low - carbon Cities, Chengdu

\begin{abstract}
The city is a major contributor to greenhouse gas emissions, with more than $70 \%$ of the world's greenhouse gas emissions coming from the city. The city is also the spatial carrier of capital, labor force and science and technology gathering, low-carbon city construction plays an important and unique role in solving the climate change problem; and the low-carbon development of the city can solve many "urban diseases" bring new opportunities for development. Chengdu low carbon development blueprint research as a "sustainable and livable city project," an important content, to explore the Chengdu in different development models to 2030 years of energy consumption and carbon emissions path, with a view to the development of Chengdu long-term development planning and related special planning to provide scientific support and recommendations.
\end{abstract}

\section{The Base of Chengdu to Create a Low-Carbon City}

Take Low-Carbon Development Actions and Measures. In 2013, Chengdu promulgated the Regulations on the Protection of Ecological Restoration in Chengdu City, and creatively established an ecological isolation zone in the suburbs of the city. It became the first city in China to introduce local regulations for ecological protection in specific areas of the city. Has issued the "Chengdu ecological civilization construction 2025 plan", "' second five "special plan to deal with climate change," "Chengdu low-carbon city construction program", "Chengdu green building action program", "Chengdu The People's Government on the construction of eco-city views "and so on. The implementation of the residents with gas ladder price system, the central city and Dujiangyan, Pengzhou, Chongzhou, Qionglai four county-level city to take the lead in the implementation of residential water ladder price system; the basic establishment of drinking water source protection, the main river cross-section water quality exceeded Payment, collective public welfare forest protection, contract energy management, enterprise carbon emission verification and other mechanisms to achieve the continuous strengthening of laws and regulations and system construction.

In January 2012, the National Development and Reform Commission decided to carry out Sino-US "sustainable and livable urban construction" project in Chengdu, which opened the prelude to Chengdu's international cooperation on climate change. To further learn from and introduce foreign low-carbon technology and advanced management experience, Chengdu to pairs of sub-way to international cooperation and low-carbon demonstration closely integrated, fully expand. Fully expand low - carbon international cooperation.

Give full play to the field of energy in the field of energy and low-carbon industries, and promote the establishment of energy and Internet industry research institutes and innovative industrial parks in Tiandu New District, Chengdu, to provide decision-making consultation and intellectual support for green and low-carbon development pilot demonstration. The completion of the 2010 list of greenhouse gas emissions in Chengdu, the deployment of 63 annual comprehensive energy consumption of 10,000 tons and above the key enterprises to carry out carbon verification, and carried out the Chengdu city carbon emissions peak and 2015 GHG emissions inventory preparation. Enhance the basic capacity of low-carbon development.

The Overall Situation of Economic Development. Economic strength continues to increase. Chengdu is the capital city of Sichuan Province, is the economic center, science and technology 
center, foreign exchange center, cultural center and integrated transport hub and other important functions of the national central city, the total economy accounted for more than $35 \%$ of Sichuan Province. "Twelfth Five-Year Plan" since the city's total economic scale steadily increased in 2015, the city's GDP reached 1080.01 billion yuan, the economic scale of the provincial cities ranked ninth, compared with 2010 growth of $68.6 \%$, an average annual growth of $10.9 \%$; Annual local public revenue 115.44 billion yuan, an average annual increase of $17.0 \%$; per capita GDP reached 12079 US dollars, the urbanization rate reached $71.3 \%$.

Environmental protection and management efforts continue to increase. Solidly promote the total amount of pollutants, chemical oxygen demand, ammonia, sulfur dioxide, nitrogen oxides and other major pollutant emissions to complete the "second five" target. Strengthen the air pollution, urban and rural water environment comprehensive management, in 2015, the proportion of good air quality to 58.6\%, PM2.5 annual average concentration of 64 micrograms / cubic meter, built 248 sewage treatment plants to achieve the central city, county, township life Sewage treatment full coverage. Strengthen the management of low-carbon waste, the completion of the first batch of national kitchen waste recycling and harmless treatment of a project (daily processing capacity of 200 tons), the basic establishment of the central city meal kitchen waste collection and transportation system; 3 large-scale living garbage environmental power plant to accelerate the construction of six planned environmental protection projects; medical waste disposal center expansion project to speed up the start of the Rafah Cement kiln co-disposal of three sludge projects, is to carry out construction waste Evaluation of site selection.

The Energy-Saving Emission Reduction in Chengdu. Energy efficiency is significantly improved and the energy consumption structure is further optimized. Energy consumption is increasing, but energy consumption growth rate is slower than GDP growth rate, and showing a downward trend. Chengdu is a typical energy input city, energy consumption mainly by electricity, natural gas and other components. In 2015, electricity, natural gas and other high-quality clean energy accounted for $51 \%$ of the proportion of energy consumption; by expanding the coal area, increase coal-fired boiler out and clean energy transformation efforts, coal consumption to further reduce the proportion of non-fossil energy accounted for primary energy consumption the proportion increased to 30.8\%. In 2015, the city's total energy consumption of 53.56 million tons of standard coal, energy elasticity coefficient of 0.63 , compared with 2010 to reduce $8.70 \%$. Energy efficiency is significantly improved in 2015, the city's unit GDP energy consumption of 0.561 tons of standard coal (79.3\% of the national average energy consumption), down $16.9 \%$ over 2010 , the full completion of the $16 \%$ reduction in the "second five" energy-saving targets.

The intensity of carbon emission control is remarkable. In 2015, the total CO2 emissions in Chengdu are about 85.37 million tons. Among them, the direct combustion of CO2 emissions of energy accounts for about $78.8 \%$ of the total. From the energy category, the main emissions from natural gas, gasoline, diesel and indirect emissions of electricity, the total emissions of about 21.8\%, $19.5 \%, 19.4 \%$ and $20.5 \%$. According to the area, industrial, construction, traffic emissions accounted for about $45.4 \%$ of the total, $17.1 \%$, 35.7\%. Carbon dioxide emissions per unit of GDP are about 0.894 tons / million, down about 19\% from 2010. Per capita CO2 emissions of 5.79 tons lower than the national average. In addition, the Sichuan carbon market in December 2016 opened the market, will be through the market mechanism to further promote the energy-saving emission reduction enterprises.

In recent years, Chengdu adhere to the "livable industry" concept into urban construction, and constantly strengthen the protection of the ecological environment, the initial construction of the "two mountains, two networks six" ecological security pattern. And comprehensively promote the construction of the ecological zone around the city, initially showing the Central City $85 \mathrm{~km}$ long, 400 meters wide green ecological landscape space and the ecological area of the lake area of the lake water area of $9.54 \%$. Actively promote the natural forest protection projects, public welfare forest construction, consolidate the results of returning farmland to forests, in 2015, the forest coverage rate of $38.4 \%$, forest volume reached 29.14 million cubic meters. Increase the urban greening landscape improvement efforts, and actively build a beautiful and beautiful village, in 
2015, the urban built area green coverage rate of 38\%, per capita park green area of 13.5 square meters / person; built a beautiful form, perfect, rich village Of the "small-scale, group-style, micro-garden, ecological" new rural complex 123.

\section{The Purpose and Significance of Chengdu Low-Carbon City Construction}

Low-carbon city construction is to break the economic development of Chengdu, energy shortages, environmental pollution between the contradictory development model. At present, Chengdu is in the transition period of industrialization and urbanization. At this stage, Chengdu's social economy will develop at a high speed, and the level of urbanization will increase rapidly, but the intensity of resource consumption will be increasing. Chengdu, the main energy resources to electricity, natural gas and coal-based, of which the most abundant natural gas resources, the current accumulation of proven natural gas reserves of 77.7 billion cubic meters, coal resources mainly in Penggu coal and Chongda coal, but because of history and economy technical reasons, the current economic development in Chengdu is still a high energy consumption, high consumption, high pollution development model. With the industrialization of Chengdu, the rapid development of urbanization, Chengdu, resource consumption and environmental pressure will be increasing. The development of low-carbon city is a development model that emphasizes the basic characteristics of low energy consumption, high efficiency, low pollution, high efficiency, low emission and high efficiency. Its development will promote the energy saving and emission reduction in various industries, reduce the carbon consumption, Alleviate Chengdu increasingly increasing resource consumption and environmental pressures, crack the economic development and energy shortages and environmental pollution between the contradictions, and ultimately promote the sustainable development of Chengdu. Chengdu low-carbon city construction has the following important significance.

It Is Conducive to the Implementation of the Central Response to Climate Change Development Strategy. The central authorities have clearly put forward the major strategies to deal with climate change and realize low-carbon development as economic and social development, and set out the objectives of China's control of greenhouse gas emissions and incorporated them into long-term planning for national economic and social development. Low-carbon urban construction is a major move to tackle climate change. In Chengdu, low-carbon city construction work is conducive to Chengdu to implement the central response to climate change development strategy, and actively take measures to continue to implement energy-saving carbon reduction, coordination of regional low-carbon development, to explore low-carbon development to promote economic development and economic transformation Structural adjustment of the sustainable development path.

It Is Conducive to Exploring the Large Central City Sustainable Development Model. Chengdu is the national central city of the new period "one way" and "Yangtze River economic zone". It is also one of the "dual core" of Chengdu-Chengdu urban agglomeration determined by the State Council, which should bear the important task of regional economic development and urbanization. Chengdu has entered the mature period of urbanization development, the resident population of more than 14 million, motor vehicle ownership after Beijing, is a typical resource input city and the "ecological deficit area", the environmental capacity is almost saturated, the basin meteorological conditions of the complex pollution, with the rapid development of the metropolis of "urban disease" increasingly obvious. Chengdu experienced the development track and the problems and challenges encountered in the national urbanization, industrialization process, with a typical. In Chengdu, low-carbon city construction work is conducive to speed up the construction of resource-intensive, beautiful environment, moderate size, rational layout, ecological and livable international metropolis, to explore the large central city sustainable development model, has important exemplary value.

It Is Conducive to Driving the Western Region to Achieve Low-Carbon Development. Low-carbon development is a new path and a new impetus for the development of economic transformation under the new normal state. It is a kind of economic development based on the clean 
and efficient use of energy, characterized by low emission, conform to the concept of sustainable development and control greenhouse gas emission form. Over the years, as the planning of the State Council to determine the main western central city, Chengdu in the western region to maintain a leading edge, the western region is the only economic scale of more than one trillion sub-provincial cities, with strong radiation and demonstration role. At present, Chengdu is in the critical period of the transition from the extensive growth mode of traditional land, capital, labor and other factors to the driving force of innovation as the main driving force. In Chengdu to carry out low-carbon city construction work, is conducive to driving in the transition period of the western region to accelerate the exploration of low-carbon development to promote harmony between man and nature symbiosis, and ultimately industrial civilization to ecological civilization across.

\section{Control Chengdu Energy Demand and Carbon Emissions Growth}

Chengdu control of the construction sector energy demand and rapid growth of carbon emissions measures are the following aspects:

Control the Size of the Population and Reduce the Demand for Construction. In 2030, by strengthening the role of radiation in Chengdu, and gradually narrow the economic gap with the surrounding areas, weakening the intensity of population migration, the resident population control in 18 million people. If the population growth is too fast and 20 million in 2030, Chengdu will be the construction sector energy demand will reach 25.6 million tons of standard coal.

Enhance Public Awareness of Energy Conservation and Environmental Protection, Control Per Capita Construction Area of Excessive Growth. Take the control of the scale of construction, the implementation of reasonable means of economic control measures, blueprint scenarios, to achieve per capita construction area of not more than 35.13 square meters, of which urban per capita construction area of not more than 31 square meters, rural areas to be controlled within 49.5 square meters. Compared with the current 30,21,49 square meters per capita construction area level, blueprint scenarios allow urban per capita construction area with the urbanization process and the improvement of living standards have some room to rise, but to strictly control the rural uptrend.

The Extensive Implementation of Building Energy Efficiency, Control of Building Area Energy Consumption Rose. Energy-saving transformation of existing buildings, the implementation of stringent energy-saving supervision of new buildings, the promotion of green buildings, universal energy-efficient appliances, in the blueprint for the situation, all building types of energy consumption per unit of decline in 2020 are showing a different range of decline The Compared to 2010, the largest increase in large public buildings should also be controlled at about $9 \%$, urban housing rose by no more than $6 \%$, rural residential and small and medium-sized public construction and even a slight negative growth.

Scientifically develop a series of sound operational regulations or normative documents that are operational and set specific carbon emissions targets and energy savings targets, as well as energy savings calculations. The development of building carbon emission measurement standards and baselines, real-time monitoring of large public buildings, residential residents to implement energy-saving labeling, in order to achieve the control of carbon emissions to provide data guidance.

To carry out the use of local resources, low-cost energy-saving wall technology, energy-saving roof typical structure optimization technology system research, as well as village life garbage collection, transportation, treatment and disposal facilities to set design specifications to achieve in the absence of air conditioning, summer indoor temperature is low At $30{ }^{\circ} \mathrm{C}$, winter higher than $10{ }^{\circ} \mathrm{C}$ village houses.

Through the energy consumption adjustment, price subsidies and other means to give full play to the construction terminal energy users to reduce energy consumption of the subjective initiative, and gradually achieve in the central heating, lighting, air conditioning and other aspects of "part of the time, part of the space" of self-regulation. 


\section{Conclusion}

(1) Chengdu build low-carbon city should focus on energy-intensive units to strengthen the energy management to proceed and the implementation of energy management projects, focusing on promoting the establishment of energy management and control center, the implementation of key energy units in the energy movement dynamic monitoring. On this basis to establish a set of enterprise-level energy management system, the system functions extended to carbon emissions management.

(2) Gradually the industrial sector, the construction sector, the transport sector, waste disposal and other aspects of energy consumption and emissions into the system, and ultimately the formation of a complete city level of energy and carbon emissions management system.

(3) We should also encourage the use of information technology and means to strengthen the production level of energy efficiency monitoring and fine management, the establishment of key energy-consuming products, energy efficiency monitoring system. For building materials, metallurgy, petrochemical and other high energy-consuming industries, to explore the establishment of the industry's main product consumption, key equipment, energy efficiency monitoring system.

\section{References}

[1] Song Ranping, Yang Shuo, Sun Miao. 2012. Energy consumption caused by the greenhouse gas emissions calculation tool guide (version 2.0). Beijing: World Resources Institute.

[2] WRI, ICLEI, C40, 2012. Global Protocol for Community-ScaleGreenhouse Gas Emissions (GPC) (PilotVersion1.0) .Availableat

http: //www.ghgprotocol.org/files/ghgp/GPC_PilotVersion_1.0_May2012_20120514.pdf.

[3] climate organization. International perspective of urban low-carbon development .2010.http: //classic.theclimategroup.org.cn/publications/2010-08-Low_Carbon_Cities-An_International_Persp ective

[4] Development of China 's Low - carbon Cities - Strategies and Methods. Beijing: China Environmental Science Press, 2011.

[5] World Resources Research Institute, Qingdao City Jiaozhou Bay Water Quality Protection Project Phase II Final Report

[6] Climate Policy Research Center, Tsinghua University. 2010 China Low Carbon Development Report. Science Press. Beijing: 2011, 2.

[7] Chen Wenjian.Study on the Motive Mechanism of Low Carbon Technology Innovation in China. Master's Thesis of Huazhong University of Science and Technology.

[8] Dai Yande, Hu Xiulian, etc. 2013. "China's carbon dioxide emission reduction technology potential and cost research." China Environmental Publishing House.

[9] National Bureau of Statistics, Urban Social and Economic Survey, 2011. China Urban Statistical Yearbook 2011. Beijing: China Statistics Press.

[10]Lei Hongpeng, Zhuang Guiyang, Zhang Chu. 2011. China's low-carbon city development: strategies and methods. Beijing: China Environmental Science Press.

[11]Liu Zhi, Andrew Salzberg. 2012. China's low-carbon city construction major drivers: local management, municipal finance and land use planning. World Bank Report: China's sustainable development of low-carbon cities. 